08-061

\title{
Consumer Demand for Prize-Linked Savings: A Preliminary Analysis
}

Peter Tufano Nick Maynard Jan-Emmanuel De Neve 


\title{
Consumer Demand for Prize-Linked Savings: A Preliminary Analysis
}

\author{
Peter Tufano* \\ Harvard Business School, NBER, and D2D Fund \\ Nick Maynard \\ D2D Fund \\ Jan-Emmanuel De Neve \\ Harvard Business School
}

\begin{abstract}
This paper reports on a small-scale survey of the potential American demand for prize-linked savings accounts, an account that awards prizes as part of the saving product's return. In October 2006, Centra Credit Union launched a prize-linked savings pilot. As part of that initiative, we conducted a mall intercept survey of over 500 people in Clarksville, Indiana, the community where the program was launched. This preliminary data suggests that low-to-moderate income Americans may have substantial demand for prize-linked savings, with a majority of survey participants expressing an interest in opening a prize-linked savings account. As predicted by theory and international experience, interest in prize-linked savings is greatest among people who do not have regular saving habits, who have little actual savings, who play lotteries extensively, and who are optimistic about their futures.
\end{abstract}

* Corresponding author contact information: Peter Tufano, Harvard Business School, Soldiers Field, Boston MA 02140 (ptufano@hbs.edu), NBER and D2D Fund; Nick Maynard, D2D Fund, 1127 Harrison Ave. Roxbury, MA 02119 (nmaynard@d2dfund.org); Jan-Emmanuel De Neve, Harvard Business School, Soldiers Field, Boston, MA 02140 (jdeneve@ @bs.edu). This analysis of survey data complements the report "Prize-Based Savings: Product Innovation to Make Saving Fun" by Nick Maynard. We would like to thank Emily McClintock Ekins, Nan Morrow, and Denise Gabel 
Prize-linked savings ("PLS") products offer savers a return in the form of the chance to earn large prizes, rather than in more traditional forms of interest or dividend income or capital appreciation. The probability of winning is typically determined by account balances, and the aggregate prize pool can be set to deliver market returns to all savers. Prize-linked assets are offered in over twenty countries around the worldincluding the U.K., Sweden, South Africa and many Latin American and Middle Eastern countries-but are not available in the United States, where state laws and federal regulations make the offering of prize-linked programs problematic. However, the demand for lotteries in the US suggests that demand for a savings vehicle offering chances to win a high payoff prize could be substantial. If so, prize-linked savings products could help raise aggregate savings among low- to-moderate income families.

Categorizing savings programs on a spectrum from coercive to exciting, Tufano and Schneider (2007) consider prize-linked savings a program that could make saving exciting, by leveraging the excitement generated by gambling and lotteries. This overlap between prize-linked savings and lotteries is important as survey results show that lowincome American families believe they are more likely to build wealth by playing the lottery than by traditional saving with compound interest (Holton, 2000; Consumer Federation of America, 2006).

Despite their long and successful history, prize-linked savings are relatively unstudied by scholars with a few exceptions. Guillen and Tschoegl (2002) survey programs around the world, describing Latin American programs in some detail. They report that in Latin America, PLS products appealed to low income and unbanked individuals. In South Africa, the Million-a-Month Account offered by South Africa's 
First National Bank (Cole et al., 2007) generated 750,000 accounts and raised over 1.2 billion Rand in two years time (Mabuza, 2007). The product reportedly has appealed to a wide cross section of South Africans.

Recent work examines the U.K. Premium Bond program (Lobe and Höltzl, 2007; Tufano, 2007), one of the longest continuously operated programs with over $£ 31.1$ billion outstanding as of March 2006. Tufano (2008) reports that demand for Premium Bonds is stronger among lower income households than is their demand for alternative products, like stocks and shares. Premium Bond sales over nearly four decades are related to savings factors (the aggregate interest rate paid on the product relative to comparable rates) as well as to gambling factors (the size of the largest prize.) Furthermore, sales are higher when aggregate savings is lower, contrary to other savings products.

All together, this work paints a picture of a savings vehicle that may appeal to people with little savings and little interest in traditional savings products. While international evidence suggests a nearly universal appeal for PLS, one might wonder whether PLS would appeal to US consumers, and if so, which ones. A more fundamental question is whether PLS would increase overall household savings, and if so, would it draw funds away from consumption, gaming or some other. This short note addresses the first of these issues—likely demand—by using market research survey techniques. 


\section{The Centra Credit Union Super Savings Pilot}

In 2007, Indiana-based Centra Credit Union launched "Super Savings," the first ever prize-linked savings product in the United States across all of its 22 branches. ${ }^{1}$ Prior to the full launch, in October 2006, a pilot and associated survey were launched in Clarksville, Indiana at a new credit union branch. The Clarksville Centra branch is located inside a Wal-Mart store, and the survey was conducted in the store by Centra contractors working in conjunction with the D2D Fund ${ }^{2}$. Table 1 lists the demographic characteristics of Clark County, the location of the pilot, and compares it with national US data. In brief, the county has a mean income $13 \%$ lower than the US mean and can provide some insight into PLS demand among low income populations. We are aware however, that the results from Clarksville may not be nationally representative.

As part of the pre-pilot market research, 547 surveys were completed by intercepting Wal-Mart customers during the mid-November to December 2006 period. The principal question asked—which is a brief description of the Super Saver accountwas the following:

Would you be interested in a savings account that awarded chances to win prizes based on the amount of money you save? The account would also have no fees, no minimum balance, and still earn interest.

This sentence-long description provided the essence of the product (prizes for savings) but obviously did not give the details, e.g., the number, size, or odds of winning the prizes, nor the relevant interest rate. It captures general interest for the product type as

\footnotetext{
${ }^{1}$ See Maynard 2007 for more detail on the Centra Super Savings experiment.

${ }^{2}$ D2D Fund is a non-profit organization that works to expand access to financial services, especially asset building opportunities, for low-income families by creating, testing and deploying innovative financial products and services (http://www.d2dfund.org/).
} 
opposed to the specific product features. In addition to collecting potential interest in the product, the survey gathered demographic information. The Appendix reproduces the survey, and Table 2 reports the results of the survey.

In total, 58\% of participants expressed a positive interest in the PLS accounts, $26 \%$ were not interested, and $16 \%$ answered "I don't know." The simple PLS concept appealed to a majority of the surveyed Wal-Mart customers in Clarksville, IN, but this finding is subject to three important caveats. First, as noted above, this population is not nationally representative but rather concentrated among low-income families. Second, since the program had not been fully marketed, this survey reflects indications of interest, not executed transactions. Finally, since the survey did not indicate the precise terms, e.g., what interest rate would be set in conjunction with the prizes, or what the prizes would be, it cannot inform about the precise demand. Nevertheless, we found that even this bare-bones description of the product was more appealing to some customers than to others, which we analyze below.

\section{The Potential Appeal of Prize-Linked Savings. ${ }^{3}$}

While delivering higher returns-e.g., higher rates of return or interest-may increase demand, psychological factors can be a potent stimulator of demand as well. Researcher in behavioral economics and behavioral finance are finding that certain systematic psychological biases can explain a great deal of consumer decisions. In this instance, the popularity of the PLS product may lie in its blend of the guarantee of no principal loss with a large, but low probability gain. PLS accounts are a textbook

\footnotetext{
${ }^{3}$ This section is adapted from Tufano 2008.
} 
application of certain behavioral economics principles. In particular, the product structure is engineered to appeal to people who are "loss averse," i.e., who will pay more to avoid a loss than to guarantee a gain of the same size. In particular, the PLS product guarantees no principal loss. However, unlike the traditional products that guarantee no principal loss (such as bank deposits, CDs, bonds), PLS leverages the behavioral phenomena that investors may avoid large gambles, but will take on small ones, in this case, the forgone interest on their invested funds. Finally, PLS reflects the behavioral factor that people often misestimate the probabilities of low-probability events (e.g. accidents or winning gambles). For a theoretical discussion of PLS products, see Pfiffelmann 2006.

The popularity of PLS products also reflects their functional properties. Alternative products with no principal loss and good liquidity are typically low-yielding demand deposit accounts. The power of compound interest provides little incentives to savers with short and uncertain savings horizons and small principal balances that generate meager amounts of interest. Instead of receiving a certain but small payout, the PLS saver gets a small chance at a large payoff. This preference mirrors the opinions revealed by a recent survey by the Consumer Federation of America (CFA) and the Financial Planning Association (FPA), which that "more than one-fifth of Americans (21\%) - 38\% of those with incomes below $\$ 25,000$ — think that winning the lottery represents the most practical way for them to accumulate several hundred thousand dollars."4

\footnotetext{
${ }^{4}$ http://www.americasaves.org/downloads/www.americasaves.org/01.09.2006.pdf
} 
Bankers offering prize-linked savings around the globe suggested that the products might particularly appeal to "non-savers," (i.e., those who had not previously been attracted to existing savings or investing products). To test this conjecture, we sought to see if the PLS structure appealed to non-savers. We considered savers to be those individuals with some form of a savings plan. They might plan to save the income of one family member, spend one's regular income but save other forms of income, or save regularly by putting money aside each month. We considered non-savers to be (for parallelism to last sentence) people who indicated that they had no regular savings plan, either spending more than their income or spending about as much as their income. Based on this categorization, $61 \%$ of all survey participants were non-savers (see Table 2). Among non-savers, $65 \%$ expressed an interest in the PLS product. Among savers, only $48 \%$ expressed an interest. Figure 1 illustrates this result graphically.

Writing about PLS accounts in Latin America, Guillén and Tschoegl (2002) conclude that "[T]he bankers we spoke with believe that (the products) are especially successful with low-income depositors." This observation is consistent with evidence on the demographics of gambling; the 1999 National Gambling Impact Study showed that $80 \%$ of gambling revenue comes from households with income less than $\$ 50 \mathrm{~K}$; the same report indicates that households with incomes less than $\$ 10 \mathrm{~K}$ spent 3 times as much gambling - in aggregate real dollars—as those with incomes greater than $\$ 50 \mathrm{~K}$. To test if PLS is especially demanded by low income and low wealth persons, the survey collected information on financial assets, including checking, savings, and money market accounts; CDs; IRAs; 401(k)s; 403(b)s; Keoghs; mutual funds; savings bonds; stocks; bonds; and any cash saved at home. The survey results by savings assets range are 
shown in Table 2 and illustrated in Figure 2. In these simple cuts, the product was most demanded among people with less savings. Among participants reporting between $\$ 1$ and $\$ 2,000$ in savings assets, $73 \%$ expressed interest in the PLS offer. In contrast, only $38 \%$ of those with $\$ 40,000$ in savings were interested.

The survey also gauged the participants' estimate of their earnings relative to the other people in the Clarksville, IN area. In general, the participants represented the full range of relative incomes. Among those participants that considered their earnings to be substantially less relative to the Clarksville population, $62 \%$ showed interest in the PLS product that was offered, while for those who thought they earned substantially more than the other people in Clarksville, IN, only $48 \%$ showed interest in the PLS offer. Table 2 also gives the results for the intermediate categories.

Because the PLS customer cannot improve the odds of winning (apart from saving more), one might expect that this activity, like gambling, may be attractive to optimistic individuals Puri and Robinson (2007) provide evidence that optimism is related to a wide range of economic decisions that include portfolio choices and labor market decisions. They find that "Optimistic people are more likely to believe that their income will grow over the next five years, even controlling for past income growth." In our survey we measure optimism by asking participants about their future expectations of their financial well-being as compared to the previous five years. We consider optimists to be those participants that replied "improve" as compared to those that considered their future expectations to either remain the same or become worse than it has been over the previous five years. Some $60 \%$ of survey participants were optimistic about their future income and only 5\% were pessimistic about their future income. Among these 
optimistic participants, 65\% showed interest in the PLS product, but only $33 \%$ of the pessimists were interested. See Table 2 and Figure 4.

Because PLS products combine saving with the thrill of winning prizes (but without the risk of losing principal), we hypothesized that PLS would appeal to lottery players and gamblers. We measure gambling and lottery activity by whether survey participants had spent over $\$ 100$ in the past 6 months on any combination of the following games: scratch-offs or pull tabs, Daily 3, Daily 4, Lucky 5, Pick 3, or Pick 4; lotteries such as Hoosier Lottery, Kentucky Cash, or Powerball, and gambling activities such as casino games or slots; and betting on horse-racing. Among all survey participants $11 \%$ reported to have spent over $\$ 100$ in the past 6 months on such games. Among this subsample of heavy lottery spenders, $75 \%$ showed interest in the PLS offer. In contrast, only $56 \%$ of the people spending less than $\$ 100$ were interested. Table 2 provides the data, and Figure 3 illustrates graphically.

Even a small substitution effect between lottery spending and prize-linked savings would lead to an increase in aggregate savings. In 2003 alone, U.S. residents spent nearly \$80 billion on legalized forms of gambling (Kearney, 2005) and \$90 billion by 2007. This amount outweighs the combined expenditure on movie tickets, recorded music, spectator sports, video games, and theme parks. Though large shares of the U.S. population engage in some form of gambling annually, evidence suggests that "on average, low-income households spend a larger percentage of their wealth on lottery tickets than other households" (Kearney, 2005: 16). If PLS can tap into this substantial demand, it might appeal to new savers. 
The survey also asked for the participants' willingness to bear financial risk. While the product has certain low risk attributes (the absence of principal loss) it also has a more risky payout (the prizes). Consistent with the notion that low income families tend to be financially risk averse, the majority of those surveyed people indicated that they were either not willing to take any financial risk or only average financial risk. Among these participants, the interest in the PLS product offer was, respectively, 54\% and 59\%. Among the fraction of participants that reported that they would be willing to take substantial risks, some $72 \%$ indicated interest in the PLS product (see Table 2).

Guillen and Tschoegl (2002) in their review of PLS programs around the world also note that the products appealed to "people outside the banking system. The Spanish banks believe, though no systemic studies exist, that [Lottery-linked deposit accounts] enabled them to grow in those Latin American countries where they introduced the accounts by attracting new customers as well as stealing customers from other banks." To test if these factors are replicated in Indiana, we hypothesized that PLS might be especially appealing to people who are unbanked or underbanked. We judged as unbanked or underbanked those participants that typically cash checks at either cashing outlets, grocery stores, Wal-Mart, convenience stores, or any other way. Banked are those survey participants that cash most of their checks at either a bank or a credit union. Among the survey participants, $20 \%$ are underbanked, of which $62 \%$ expressed interested in the PLS product. Among the $80 \%$ of survey participants that are "banked," $58 \%$ showed interest. Table 2 provides the data.

A number of other factors might relate to the demand for PLS. A number of authors, e.g., Campbell (2006), Agarwal, Driscoll, Gabaix and Laibson (2007), and 
Barber and Odean (2001) have found that financial decision making varies with education, age and gender. These traits may capture a variety of factors, ranging from financial sophistication, risk taking, or unobserved long-run wealth and income. To assess these qualities, we also collected data on gender, age, employment status, education, marital status, household size, and financial literacy. These are reported in Table 2 as well. In these simple cross tabs, there is slightly stronger demand among younger persons, men, employed people, less educated persons and certain types of households.

\section{Expressed Preferences: Multivariate Analyses}

The discussion above reports univariate differences between people who expressed a positive interest in PLS versus those expressing a negative interest. However, many of the variables are correlated with one another. For example, the level of savings is negatively correlated with being a non-saver $(\rho=-0.26)$. Optimistic income expectations drop with increases in age among survey participants $(\rho=-0.38)$. Being fulltime employed correlates positively with optimistic income expectations $(\rho=0.31)$. These correlations require a multivariate analysis.

Table 3 shows the results of a multivariate logistic regression of expressed interest in the offered PLS account using the explanatory variables discussed above that reflect demographic and socio-economic characteristics. We report two analyses, one that compares the interested individuals with those that were either not interested or replied that they didn't know (full sample). The second panel contrasts the interested individuals directly with those that were not interested, ignoring those who expressed no opinion (the 
restricted sample). The logistic form produces odds ratios that allow for the prediction of an individual's propensity to take up PLS products.

As predicted by international anecdotal evidence, the product appeals to nonsavers in this expanded analysis. First, the expressed preference is stronger for people who do not claim to have regular savings plans, i.e., those who either state that they do not save or merely save if they happen to have money that they haven't spent that month. As compared to individuals or households with a savings plan (i.e. they save the income of one family member, put money aside regularly each month, etc.), a non-saver is $70 \%$ more likely to show interest in the PLS product. This large result is statistically significant at the $5 \%$ level.

In addition to being related to savings plans, PLS demand is related to the level of savings, with the product appealing most to people with almost no savings. As compared to participants that reported having $\$ 50,000$ or more in financial assets, participants whose financial assets are in the $\$ 1-\$ 2,000$ range show a propensity for interest in the offered PLS product that is 2.5 times greater, significant at 5\% and $10 \%$ levels for the two samples.

A third predictor for interest in PLS accounts is optimism, measured by the belief that one's financial well-being will improve over the next five years. Optimistic participants are 2.1 to 2.5 times more likely to show interest in the PLS product than those who foresee no change in their income over the coming five years. This positive correlation is significant at the $1 \%$ level for both data panels. Conversely, individuals that held negative expectations on their future income levels had similar levels of interest to 
those who expected no growth in future income. The result is consistent with emerging academic work on the relationship between optimism and financial decision-making.

Another factor associated with strong demand in the PLS product is being a heavy spender on lottery and gambling activities. Participants that had spent $\$ 100$ or more over the past 6 months on such games had interest levels 2.9 or 2.6 times higher than those participants that had spent less than $\$ 100$. An important question for future research is whether this interest in PLS would add to or substitute for demand for lottery play by these individuals.

A few other explanatory variables are related to demand. Persons in the 55-64 age group are less interested in the PLS account with an odds ratio of 0.4 or 0.3 as compared to the youngest age group in our sample (18-24). Separated individuals show substantially more interest in the PLS product compared to married individuals (the odds ratio stands at 9.3 and shows significance at the $5 \%$ level). Counter to our joint measure for lottery and gambling expenses, the stand-alone activity of gambling (measured in the survey by playing the casino and horse-races) produces an odds ratio that predicts only half as much interest (0.49) relative to non-gamblers. This result is significant at the $10 \%$ level for the full sample only. While it is mere supposition, PLS may be closer in form to the "tame" gaming embodied in lottery play than to the more active gambling of casino or horse-racing.

In the multivariate specifications shown in Table 3, a number of variables are not significant, notwithstanding theoretical conjectures that they could be important. These include the stated financial risk profile of the survey participants and the self-assessed relative earnings. Furthermore, access to financial services, financial literacy, gender, 
employment status, household size, and education were not strongly related with interest in the PLS product after controlling for other factors.

\section{Conclusion}

The Centra survey results provide a first look into demand for PLS in America. While merely demonstrating expressed (as opposed to revealed) demand, the results are still promising on a few dimensions. First, among the low income population we studied, there was substantial interest in a savings product that provides prizes as part of its return. Second, this product appeals to non-savers, who do not save with traditional products. Third, the product appeals to heavy lottery players, and by virtue of this fact, has the potential of turning their gambling activities into demand for savings.

As promising as we find this analysis, it is important to keep in mind the uphill battle that PLS products face in the US due significantly to well-established gambling and lottery industries that might oppose PLS and the roadblocks due to legal uncertainty and prohibitions around this new product. Furthermore, businesses or state treasurers might be reluctant to innovate around a product that must compete against heavily marketed alternatives. Nevertheless, our preliminary PLS findings suggest that the product is promising, despite the formidable barriers to its success in the US. 


\section{Sources}

Agarwal, S., Driscoll, J., Gabaix, X. and Laibson, D. (2007) "The Age of Reason: Financial Decisions Over the Lifecycle". MIT Department of Economics Working Paper No. 07-11 Available at SSRN: http://ssrn.com/abstract=973790

Campbell, J. (2006) “Household Finance.” The Journal of Finance, Vol. LXI, No. 4, August.

Cole, S., Tufano, P., Schneider, D., and Collins, D. (2007) "First National Bank's Golden Opportunity," Harvard Business School Case 208-072.

Consumer Federation of America (2006) "How Americans View Personal Wealth vs. How Financial Planners View This Wealth." Consumer Federation of America, Washington, D.C.

Guillen, M. and Tschoegl, A. (2002) "Banking on Gambling: Banks and Lottery-Linked Deposit Accounts," Journal of Financial Services Research, Vol. 21, No. 3.

Holton, L. (2000) "Redefining the Rainy Day." American Demographics 22:6.

Kearney, M. (2005) "The Economic Winners and Losers of Legalized Gambling." National Tax Journal, 58:281-302.

Lange, M. (2007) "States That Allow Gambling Soak the Poorest Residents," Deseret Morning News, May 6.

Lobe, Sebastian and Alexander Hölzl. 2007. "Why are British Premium Bonds so Successful? The Effect of Saving With a Thrill." Available at SSRN: http://ssrn.com/abstract $=992794$

Mabuza, E. (2007) “FNB 'Lottery' Still on Pending New Appeal.” Business Day (Johannesburg), April 18.

Maynard, N. (2007) "Prize-Based Savings: Product Innovation to Make Saving Fun" Doorways to Dreams Fund Report. Available at http://www.d2dfund.org/downloads/2007_12_PrizeBasedSavings-CreditUnionsFinal.pdf (visited January 22, 2008).

National Gambling Impact Study Commission. June 18, 1999. National Gambling Impact Study Final Report. Washington DC.

Odean, T. and Barber, B. (2001) "Boys will be Boys: Gender, Overconfidence, and Common Stock Investment," Quarterly Journal of Economics, February, Vol. 116, No. 1, 261-292. 
Pfiffelmann, M. (2006) "Which optimal design for LLDAs?" Laboratoire de Recherche en Gestion et en Economie Working Paper 2006-78.

Puri, M. and Robinson, D. (2007) "Optimism and Economic Choice.” Journal of Financial Economics, 86: 71-99.

Tufano, P. (2008) "Saving whilst Gambling: An Empirical Analysis of U.K. Premium Bonds." American Economic Review, May 2008 (Papers and Proceedings).

Tufano, P. and Schneider, D. (2007) "Using Financial Innovation to Support Savers: From Coercion to Excitement." Forthcoming in Access, Assets and Poverty, ed. Rebecca Blank and Michael Barr (Russell Sage). 
Figure 1: PLS Consumer Demand and Saving Habits

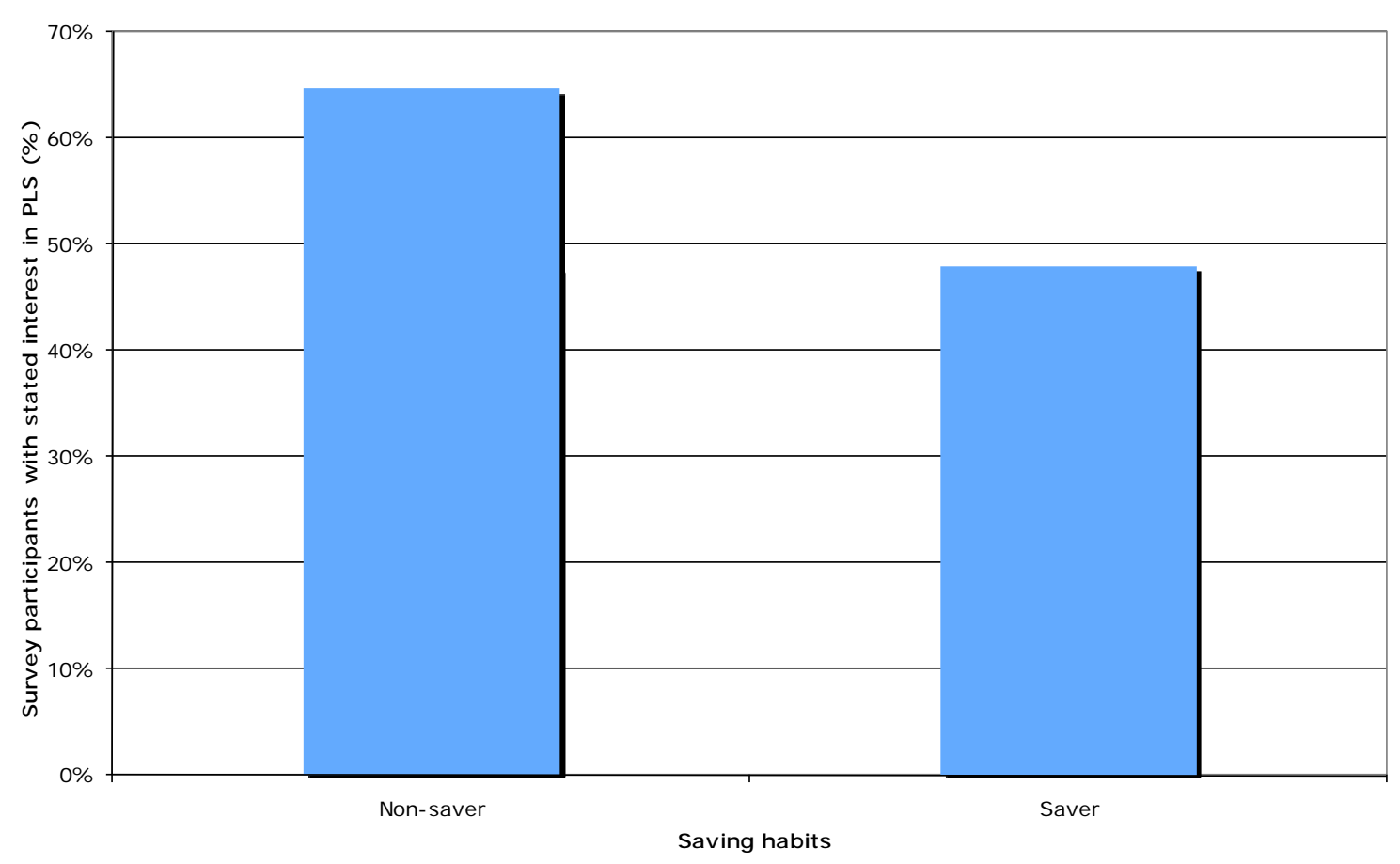

Figure 2: PLS Consumer Demand and Savings Assets

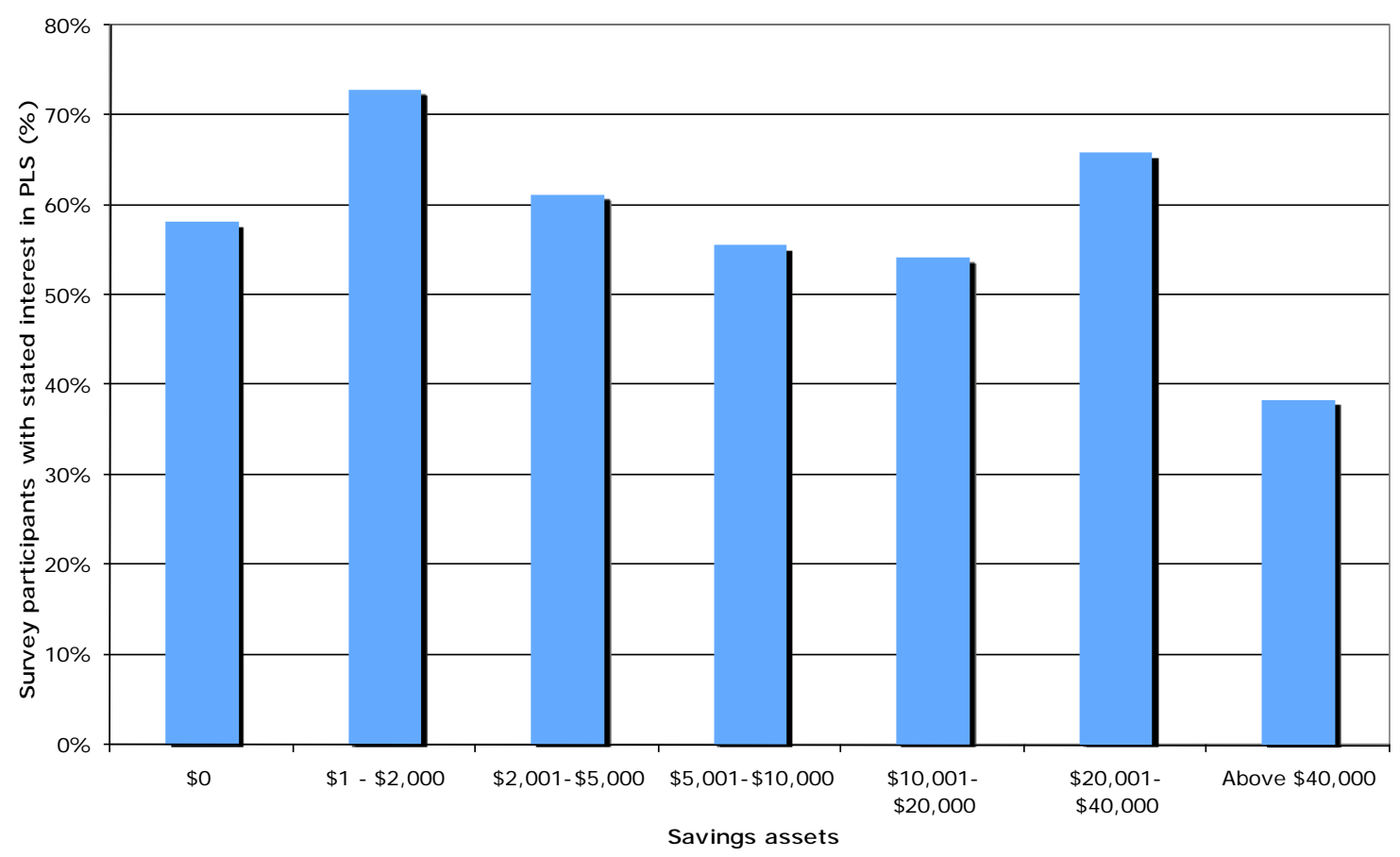


Figure 3: PLS Consumer Demand and Lottery Spending

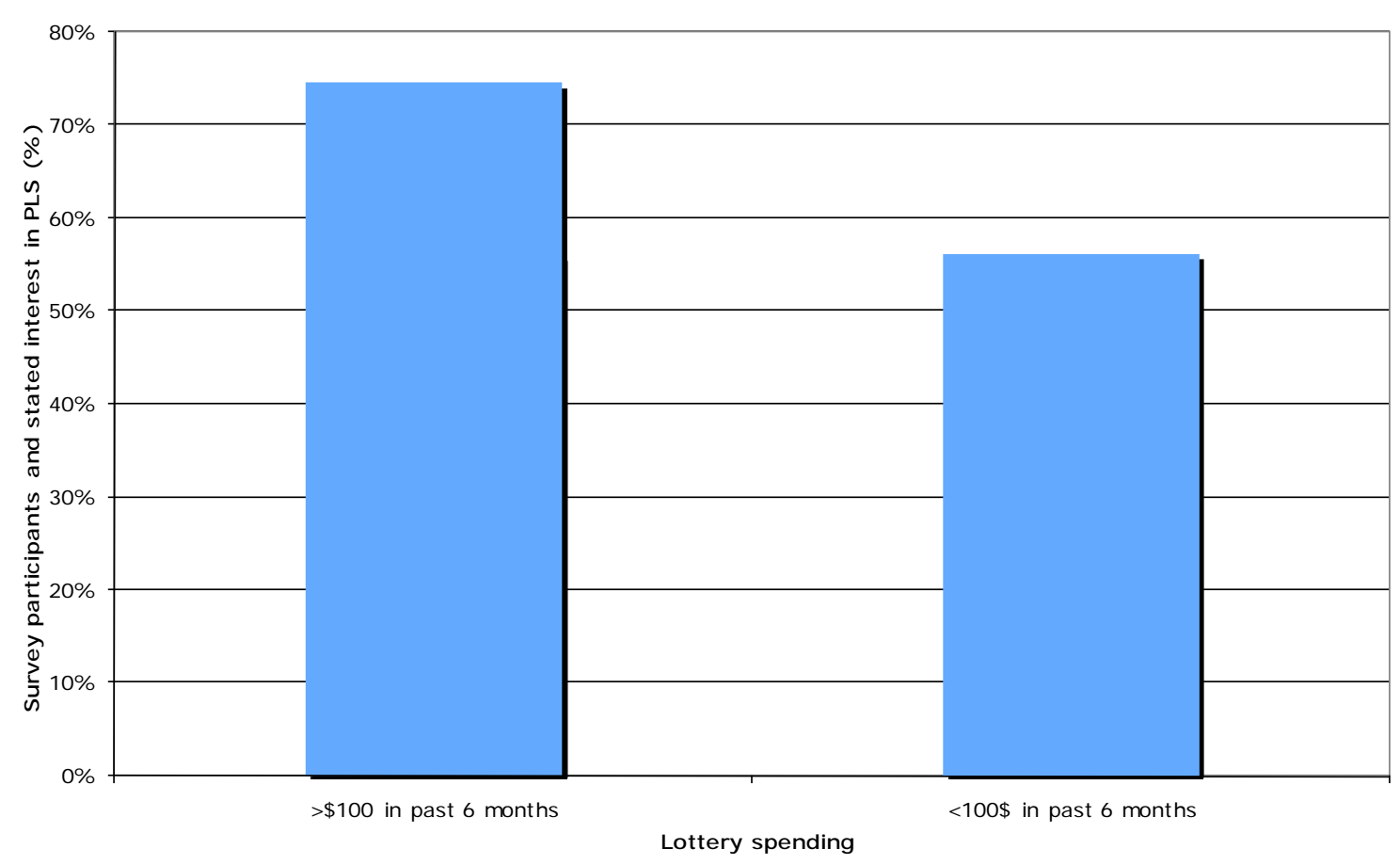

Figure 4: PLS Consumer Demand and Future Income Expectations

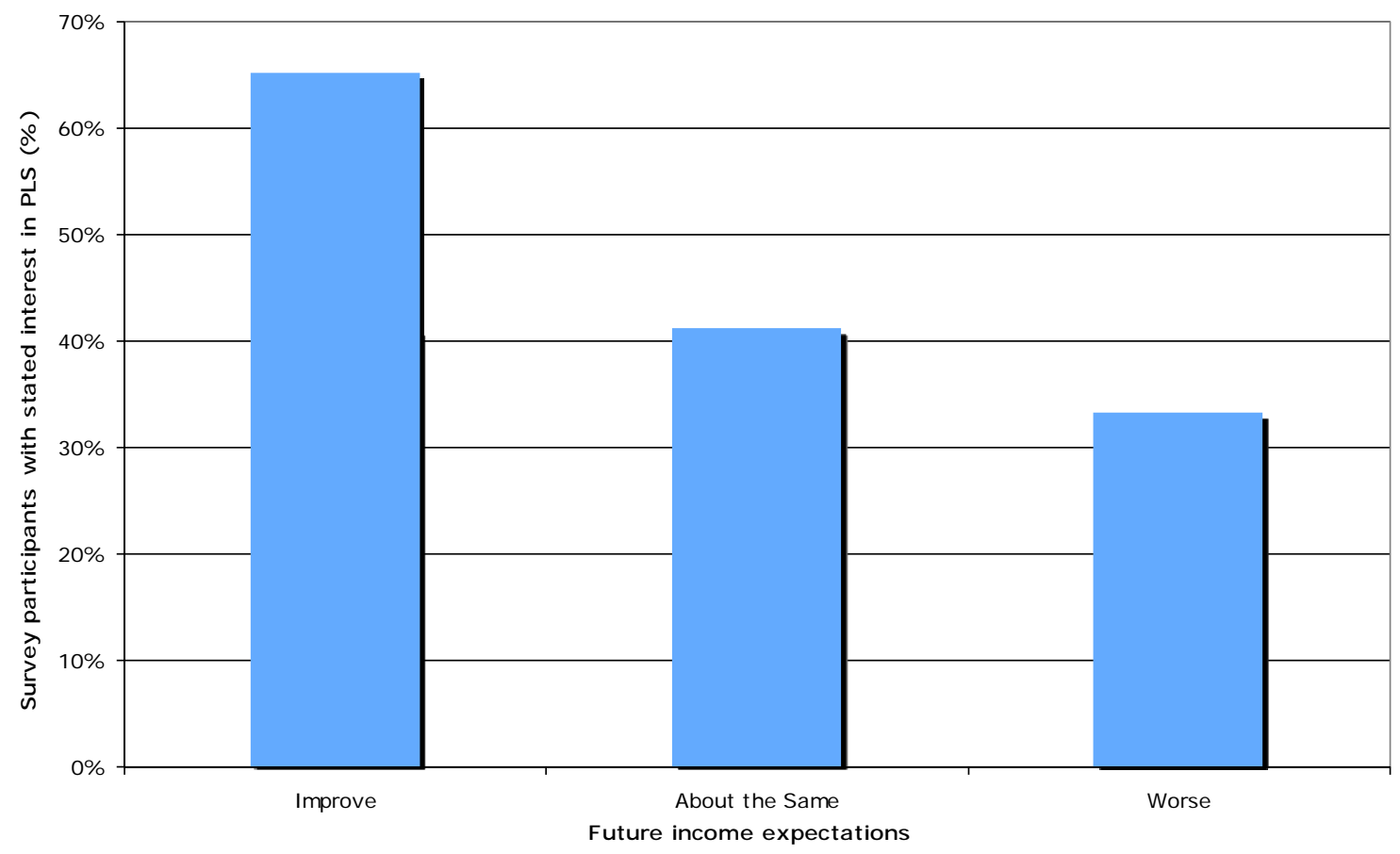


Figure 5: PLS Consumer Demand and Age

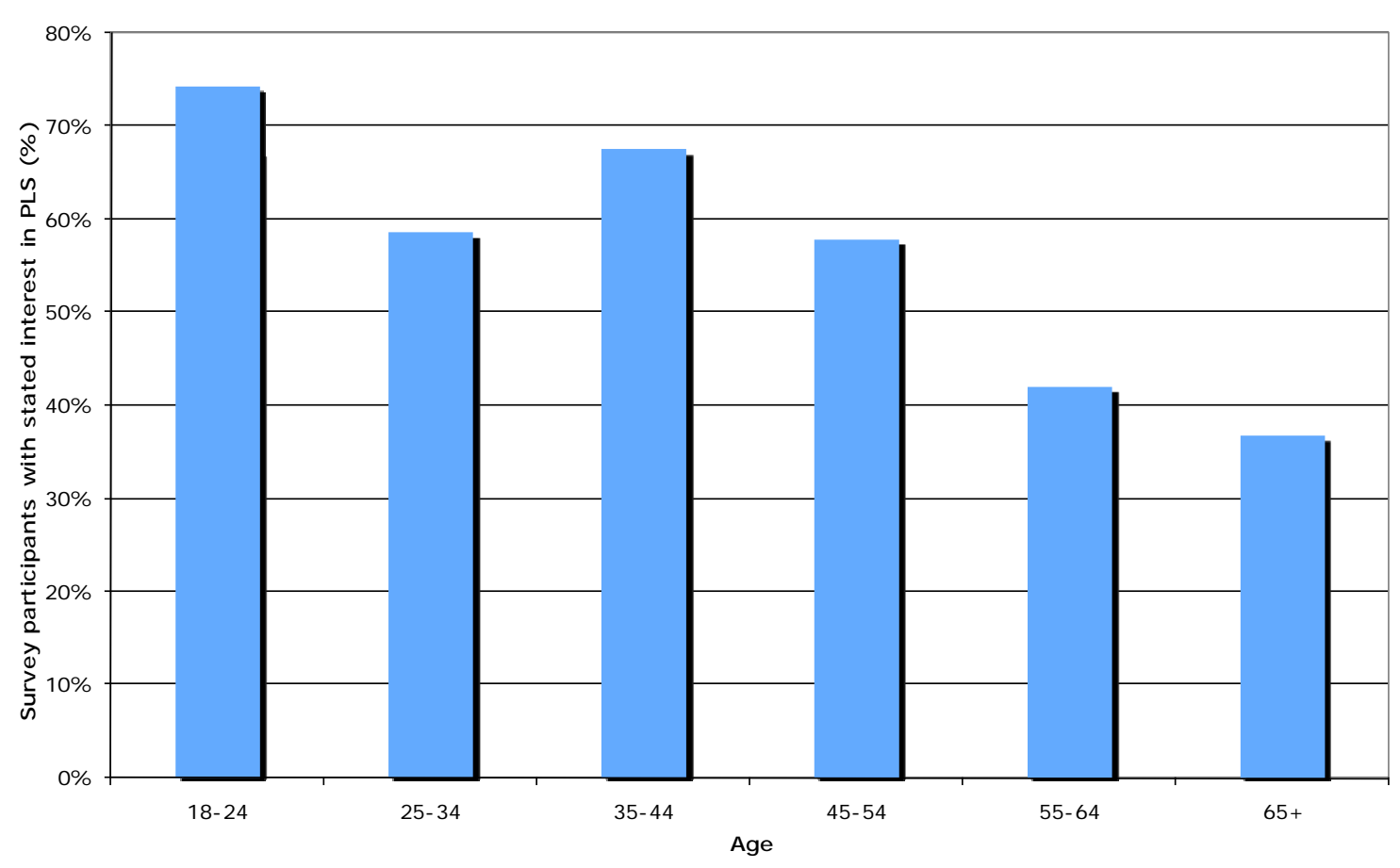


Table 1. Demographic characteristics of Clark County, Indiana versus USA, 2006 Census

POPULATION

\section{INCOME AND BENEFITS (IN 2006 INFLATIONADJUSTED DOLLARS)}

Total households

Less than $\$ 10,000$

$\$ 10,000$ to $\$ 14,999$

$\$ 15,000$ to $\$ 24,999$

$\$ 25,000$ to $\$ 34,999$

$\$ 35,000$ to $\$ 49,999$

$\$ 50,000$ to $\$ 74,999$

$\$ 75,000$ to $\$ 99,999$

More than $\$ 100,000$

Median household income

Mean household income

\section{EDUCATIONAL ATTAINMENT}

Population 25 years and over

Less than 9th grade

$9^{\text {th }}$ to 12 th grade, no diploma

High school graduate (includes equivalency)

Some college, no degree

Associate's degree

Bachelor's degree

Graduate or professional degree
Clark County

103,569
USA

$299,398,485$

$\begin{array}{rrrr}\mathbf{4 4 , 4 6 4} & & \mathbf{1 1 1 , 6 1 7 , 4 0 2} & \\ 3,565 & 8 \% & 8,898,696 & 8 \% \\ 2,885 & 6 \% & 6,639,877 & 6 \% \\ 5,832 & 13 \% & 12,721,628 & 11 \% \\ 5,920 & 13 \% & 12,446,822 & 11 \% \\ 7,864 & 18 \% & 16,511,457 & 15 \% \\ 8,458 & 19 \% & 21,221,889 & 19 \% \\ 5,968 & 13 \% & 13,214,551 & 12 \% \\ 3,972 & 9 \% & 19,962,482 & 18 \% \\ \$ 41,719 & & \$ 48,451 & \\ \$ 50,860 & & \$ 65,527 & \end{array}$

70,693

$195,932,824$

3,294

8,789

26,147

16,908

4,856

7,568

3,131

$5 \%$

$12,743,555$

$12 \%$

$37 \%$

$24 \%$

$7 \%$

$11 \%$

$4 \%$

$18,502,540$

$59,123,954$

$38,185,678$

$14,486,202$

$33,496,187$

$19,394,708$

$7 \%$

$9 \%$

$30 \%$

$19 \%$

$7 \%$

$17 \%$

$10 \%$

\section{MARITAL STATUS}

Males 15 years and over

40,116

Never married

Now married, except separated

Separated

Widowed

Divorced

11,675

21,609

774

1,665

4,393

43,252

Females 15 years and over

Never married

Now married, except separated

Separated

Widowed

Divorced

10,642

20,167

1,491

5,326

5,626

$29 \%$
$54 \%$
$2 \%$
$4 \%$
$11 \%$

$116,327,232$

$39,401,560$

$60,955,218$

$2,194,345$

$2,959,354$

$10,816,755$

$34 \%$

$52 \%$

$2 \%$

$3 \%$

$9 \%$

$\mathbf{1 2 2 , 2 5 8 , 4 5 0}$

$25 \% \quad 33,385,649$

$47 \%$

$59,211,138$

$3,210,647$

$3 \%$

$12,223,537$

$14,227,479$

$27 \%$

$48 \%$

$3 \%$

$10 \%$

$13 \%$

$12 \%$

\section{RACE}

White

Black or African American

American Indian and Alaska Native

Asian

91,844

$89 \%$

$221,331,507$

$74 \%$

7,557

$7 \%$

$37,051,483$

$12 \%$

2,760

$0 \%$

$2,369,431$

$1 \%$

Hispanic or Latino (of any race)

$0 \%$

$13,100,095$

$44,252,278$
$4 \%$

$15 \%$

Source: http://factfinder.census.gov/ (last visited on December 6, 2007) 
Table 2. Results from the Centra Credit Union survey in Clarksville, Indiana, November-December 2006

Shows the number and percentage results of the survey broken down by the characteristics of the respondents. The survey question asked: "Would you be interested in a savings account that awarded chances to win prizes based on the amount of money you save? The account would also have no fees, no minimum balance, and still earn interest."

Percentage of Group by Preference

\section{All Respondents:}

Respondents by characteristics:

Saving habits
$\quad$ Non-saver ${ }^{1}$
$\quad$ Saver
Savings assets
$\quad \$ 0$
$\$ 1-\$ 2,000$
$\$ 2,001-\$ 5,000$
$\$ 5,001-\$ 10,000$
$\$ 10,001-\$ 20,000$
$\$ 20,001-\$ 40,000$

Above $\$ 40,000$

Earnings relative to Clarksville, IN population

Substantially more

Little more

About the same

Little less

Substantially less

Future income expectations

Improve

About the Same

Worse

Lottery spending

More than $\$ 100$ in past 6 months

Less than $100 \$$ in past 6 months

Investment risk profile

High financial risk profile

Above average financial risk profile

Average financial risk profile

No financial risk

Financial services

Banked $^{2}$

Unbanked

Financial literacy ${ }^{3}$

More literate

Less literate
331

215

55

144

80

54

59

44

94

31

112

262

94

42

392

126

27

59

488

25

67

217

232

431

112

225

320
Yes, I'm interested

$58 \%$

$65 \%$

$48 \%$

$58 \%$

$73 \%$

$61 \%$

$56 \%$

$54 \%$

$66 \%$

$38 \%$

$48 \%$

$58 \%$

$59 \%$

$56 \%$

$62 \%$

$65 \%$

$41 \%$

$33 \%$

$75 \%$

$56 \%$

$72 \%$

$61 \%$

$59 \%$

$54 \%$

$58 \%$

$62 \%$

$56 \%$

$59 \%$
No. I'm not interested $26 \%$

$21 \%$

$33 \%$

$14 \%$

$19 \%$

$29 \%$

$15 \%$

$28 \%$

$26 \%$

$20 \%$

$20 \%$

$41 \%$

$39 \%$

$25 \%$

$26 \%$

$24 \%$

$24 \%$

$20 \%$

$40 \%$

$44 \%$

$15 \%$

$27 \%$

$24 \%$

$27 \%$

$24 \%$

$28 \%$

$26 \%$

$25 \%$

$28 \%$

$24 \%$
$10 \%$

$17 \%$

$17 \%$

$13 \%$

$16 \%$

$13 \%$

$13 \%$

$11 \%$

$19 \%$

$25 \%$

$14 \%$

$20 \%$

$13 \%$

$17 \%$

$15 \%$

$19 \%$

$14 \%$

$15 \%$

$19 \%$

$22 \%$

$4 \%$

$12 \%$

$18 \%$

$17 \%$

$16 \%$ 
Table 2 (continued)

\section{All Respondents}

Age groups

18-24

25-34

$35-44$

45-54

$55-64$

$65+$

Gender

Male

Female

Employment status

Full-Time

Part-Time

Student

Retired

Work in the Home

Unemployed

Marital Status

Married

Living with a partner

Widowed

Divorced

Separated

Never Married

\section{Education}

No high school degree

High school degree

Some College

Associate and technical degree

College and postgraduate degree

Household size

Household with 5 or more members

Household with 4 members

Household with 3 members

Household with 2 members

Household with 1 member

Percentage of group by preference

Sample
(number)

547

74

87

120

135

81

49

160

386

315

56

13

79

24

60

255

65

28

78

23

98

40

199

157

70

81

73

77

115

184

98
Yes, I'm interested $58 \%$

$74 \%$

$59 \%$

$68 \%$

$58 \%$

$42 \%$

$37 \%$

$62 \%$

$56 \%$

$63 \%$

$63 \%$

$38 \%$

$44 \%$

$50 \%$

$57 \%$

$51 \%$

$68 \%$

$50 \%$

$58 \%$

$74 \%$

$68 \%$

$55 \%$

$62 \%$

$59 \%$

$59 \%$

$49 \%$

$52 \%$

$69 \%$

$60 \%$

$52 \%$

$64 \%$
No. I'm not interested

$26 \%$

$\begin{array}{ll}14 \% & 12 \% \\ 23 \% & 18 \% \\ 16 \% & 17 \% \\ 25 \% & 17 \% \\ 43 \% & 15 \% \\ 47 \% & 16 \%\end{array}$

$26 \%$

$26 \%$

$20 \%$

$30 \%$

$23 \%$

$41 \%$

$33 \%$

$28 \%$

$30 \%$

$15 \%$

$39 \%$

$28 \%$

$9 \%$

$19 \%$

$25 \%$

$24 \%$

$24 \%$

$24 \%$

$37 \%$

$22 \%$

$16 \%$

$23 \%$

$34 \%$

$24 \%$
$13 \%$

$18 \%$

Don't know $16 \%$

\section{$\%$ \\ $7 \%$ \\ $6 \%$}

$17 \%$

$5 \%$

$17 \%$

$7 \%$

$38 \%$

$15 \%$

$17 \%$

$15 \%$

$18 \%$

$17 \%$

$11 \%$

$14 \%$

$17 \%$

$12 \%$

$20 \%$

$15 \%$

$18 \%$

$17 \%$

$14 \%$

$26 \%$

$16 \%$

$17 \%$

$14 \%$

$11 \%$ 


\section{Notes to Table 2}

${ }^{1}$ Savers are those survey participants that show saving habits that are indicative of some form of savings plan. This could be saving habits that save income of one family member, that spend regular income but save other forms of income, or save regularly by putting money aside each month. Non-savers are survey participants that have no regular savings plan by either spending more than their income or about as much as their income.

${ }^{2}$ Banked are those survey participants that cash most of their checks at either a bank or a credit union. Unbanked are those participants that typically cash checks at either cashing outlets, grocery stores, Wal-Mart, convenience stores, or any other way.

${ }^{3}$ Participants deemed more financially literate are considered to be those survey participants that knew the answer to the following question: "Imagine that the interest rate on your savings account was $1 \%$ per year and inflation was $2 \%$ per year. After 1 year, would you be able to buy more than today, exactly the same as today, or less than today with the money in this account?" 
Table 3. Multivariate logistic regression of expressed interest in Centra Credit Union PLS account on demographic and socio-economic characteristics.

The full sample compares those expressing a positive interest to all others (that are those without an interest and those selecting "don't know" as their interest). The sample "expressing opinions" excludes those who selected "Don't know." The discrete variables that were omitted for fixed effects can be identified by comparison with Table 2 . This table produces odds ratios with levels of statistical significance indicated as follows: $* * * \mathrm{p}<0.01, * * \mathrm{p}<0.05, * \mathrm{p}<0.1$.

Variable

Saving habits

Non-saver ${ }^{1}$

Savings assets

$\$ 0$

$\$ 1-\$ 2,000$

$\$ 2,001-\$ 5,000$

$\$ 5,001-\$ 10,000$

$\$ 10,001-\$ 20,000$

$\$ 20,001-\$ 40,000$

Earnings relative to Clarksville, IN population

Substantially more

Little more

About the same

Little less

Future income expectations

Improve

Worse

Lottery spending

More than $100 \$$ in past 6 months

Financial risk profile

High financial risk

Above average financial risk

Average financial risk

Financial services

Banked $^{2}$

Financial literacy ${ }^{3}$

Less financially literate

Age groups

25-34

$35-44$

45-54

55-64

$65+$

Gender

Male

\section{Full sample}

1.523

$2.456 * *$

1.561

1.258

1.341

$2.409 *$

0.672

0.848

0.871

0.829

$2.108 \quad * * *$

0.641

$2.893 * * *$

1.741

1.232

1.266

0.832

1.141

1.243

0.548

0.931

0.635

$0.440 *$

0.445

0.896

\section{Sample expressing} Opinions
1.004

1.272

1.198

1.528

2.453

0.420

0.673

0.716

0.776

0.748

1.093

0.880

1.201

0.837

0.461

0.916

0.519

0.354

0.799

$2.184 *$

$2.454 \quad * * *$

$2.578 \quad * *$

0.315 ** 


\section{Table 3 (continued)}

\section{Employment status}

Full-Time

Part-Time

Marital Status

Widowed

Divorced

Separated

Never Married

Education

High school degree

Some college

Associate and technical degree

College and postgraduate degree

Household size

${ }^{1}$ Savers are those survey participants that show saving habits that are indicative of some form of savings plan. This could be saving habits that save income of one family member, that spend regular income but save other forms of income, or save regularly by putting money aside each month. Non-savers are survey participants that have no regular savings plan by either spending more than their income or about as much as their income.

\footnotetext{
${ }^{2}$ Banked are those survey participants that cash most of their checks at either a bank or a credit union. Unbanked are those participants that typically cash checks at either cashing outlets, grocery stores, Wal-Mart, convenience stores, or any other way.

${ }^{3}$ Participants deemed more financially literate are considered to be those survey participants that knew the answer to the following question: "Imagine that the interest rate on your savings account was $1 \%$ per year and inflation was $2 \%$ per year. After 1 year, would you be able to buy more than today, exactly the same as today, or less than today with the money in this account?"
} 


\section{Appendix: Survey}

\section{Question 1}

Do you currently have an account at Centra Credit Union?
A. Yes
B. No

\section{Question 2}

Would you be interested in a savings account that awarded chances to win prizes based on the amount of money you save? The account would also have no fees, no minimum balance, and still earn interest?
A. Yes
B. No
C. Don't know

\section{Question 3}

Over the last six months, where did you go to cash most of your checks?
A. Credit Union
B. Bank
C. Check Cashing Outlet
D. Grocery Store
E. Wal-Mart
F. Convenience Store
G. Other

\section{Question 4}

Which of the following statements best describes your saving habits?
A. Usually spend more than income
B. Usually spend about as much as income
C. Save whatever is left over at the end of the month--No regular plan
D. Save income of one family member, spend the other
E. Spend regular income, save other income
F. Save regularly by putting money aside each month

\section{Question 5}

Some investments offer higher returns but are more risky. Risk means you could lose some of the money you invested. Which of the statements below best describes the amount of financial risk that you [and your spouse] are willing to take when you save or make investments?
A. Take substantial risks expecting to earn substantial returns
B. Take above average financial risks expecting to earn above average returns.
C. Take average financial risks expecting to earn average returns.
D. Not willing to take financial risks. 


\section{Question 6}

If you [and your spouse] were to add up all of your savings accounts and financial assets today (including checking, savings, and money market accounts; CDs; IRAs; 401(k)s; 403(b)s; Keoghs; Mutual Funds; Savings Bonds; Stocks; Bonds; or any cash saved at home), approximately how much would they amount to?
A. $\$ 0$
B. $\$ 1$ to $\$ 2,000$
C. $\$ 2001$ to $\$ 5,000$
D. $\$ 5001$ to $\$ 10,000$
E. $\$ 10,001$ to $\$ 20,000$
F. $\$ 20,001$ to $\$ 40,000$
G. Above $\$ 40,000$

\section{Question 7}

Imagine that the interest rate on your savings account was $1 \%$ per year and inflation was $2 \%$ per year. After 1 year, would you be able to buy more than today, exactly the same as today, or less than today with the money in this account? [Or you don't know?]
A. More than today
B. Exactly the same
C. Less than today
D. Don't Know

\section{Question 8}

Relative to all the people here in Clarksville and around this area, do you think you earn substantially more, a little more, about the same, a little less, or substantially less?
A. Substantially more
B. Little more
C. About the same
D. Little less
E. Substantially less

\section{Question 9}

I'd like to ask you about your expectations for the future. Over the next five years, do you expect your financial well being to improve, become worse, or remain the same as it has over the previous five years?
A. Better
B. Worse
C. About the same

\section{Question 10}

Where do you go for the latest news and traffic updates?
A. Internet
B. Cell Phone
C. Radio
D. TV
E. Newspaper

\section{Question 11}

Which radio station do you listen to most?
A. 840 AM (WHAS)
B. 97.5 (WAMZ)
C. 90.9 (WKUE)
D. 105.1 (WLRS)
E. 102.3 (WXMA)
F. Other
G. I don't listen to the radio 


\section{Question 12}

Which newspaper do you read most often?
A Louisville Courier-Journal
B. Jeffersonville Evening News
C. New Albany Tribune.
D. Other local paper
E. Other national paper
F. I don't read the newspaper

\section{Question 13}

If you read the newspaper, which section do you like the most?
A. Main News
B. Sports
C. Life Style
D. Velocity / Entertainment
E. Editorial

\section{Questions 14-18}

\section{(HAVE THE SAME ANSWER CHOICES)}
A. Yes, regularly
B. Yes, somewhat regularly
C. Yes, but rarely
D. No

\section{Question 14}

Do you play scratch-offs or pull tabs?

\section{Question 15}

Do you play games like Daily 3, Daily 4, Lucky 5, Pick 3, or Pick 4?

\section{Question 16}

Do you play the Lottery, such as Hoosier Lottery, Kentucky Cash, or Powerball?

\section{Question 17}

Do you play games or slots at riverboat casinos?

\section{Question 18}

Do you bet on horse-racing?

\section{Question 19}

In the last six months, about how much do you think you have spent on these games?
A. $\$ 0$
B. Less than $\$ 50$
C. $\$ 50-\$ 100$
D. $\$ 101-200$
E. $\$ 201+$

\section{Question 20}

What is your age group?
A. $18-24$
B. $25-34$
C. $35-44$
D. $45-54$
E. $55-64$
F. $65+$ 


\section{Question 21}

Are you currently married, living with a partner, separated, divorced, widowed, or have you never been married?
A. Married
B. Living with a partner
C. Widowed
D. Divorced
E. Separated
F. Never Married

\section{Question 22}

How many people [including YOURSELF] live in your household?
A. 1
B. 2
C. 3
D. 4
E. $5+$ (Five or More)

Question 23

What was your last grade completed?
A. Less than high school
B. High school
C. Some college
D. Associates degree
E. Bachelors
F. Post-Graduate degree
G. Technical degree

\section{Question 24}

Are you employed:
A. Full time
B. Part time
C. I'm a student
D. I'm a retired
E. I work in the home

F. Unemployed 